Kitap Eleştirisi

\title{
Geçmiş ve Gelecek Arasında Yeni Medya Kültürleri ve Dijital Kültür Arkeolojileri
}

\author{
Illker Erdoğan \\ Doçent. Dr. \\ İzmir Kâtip Çelebi Üniversitesi \\ Sosyal ve Beşeri Bilimler Fakültesi \\ Medya ve İletișim Bölümü \\ ilkgazeteci@gmail.com \\ Orcid: 0000-0002-6690-4681
}

Parikka, J. (2017). Medya Arkeolojisi Nedir?

(E. Kılıç, Çev.). İstanbul: Koç Üniversitesi Yayınları

\section{Abstract \\ New Media Cultures and Archaeologies of Digital Culture between Past and Future}

What is Media Archaeology?, written by Jussi Parikka, responds to questions such as 'what are the conditions of existence of this thing, of that statement, of these discourses and the multiple media(ted) practices with which we live?', and 'what do we do with media theory?' The book offers an insight into how to think media archaeologically in contemporary culture, and maps the various theories, methods and ideas that give us guidance on how to do that. In his book, Parikka deals with media archaeology through old and new media, imaginary media, new materialism, noise and archive.

Keywords: Media archaeology, new media cultures, archaeologies of digital culture 


\section{Résumé}

\section{Cultures des nouveaux médias et archéologies de la culture numé- rique entre passé et futur}

Qu'est-ce que l'archéologie des médias?, écrit par Jussi Parikka, répond à des questions telles que: 'Quelles sont les conditions d'existence de cette chose, de cette déclaration, de ces discours et des multiples pratiques (médiatiques) avec lesquelles nous vivons?' et 'que faisons-nous avec la théorie des médias?' Le livre offre un aperçu de la manière de penser les médias de manière archéologique dans la culture contemporaine et dresse une carte des différentes théories, méthodes et idées qui nous guident dans cette voie. Dans son livre, Parikka traite de l'archéologie des médias à travers les médias anciens et nouveaux, les médias imaginaires, le nouveau matérialisme, le bruit et les archives.

Mots-clés: L'archéologie de média, les cultures de nouveaux médias, archéologies de la culture numérique

\section{Öz}

Jussi Parikka tarafindan yazılan Medya Arkeolojisi Nedir? adlı kitap, 'yaşamımızı sürdürürken kullandığımız şu şeyin, bu ifadenin, şu söylemlerin, medya aracılığıyla yaşadığımız çok sayıda pratiğin varoluş koşulları nedir?' ve 'medya teorisi ne işimize yarar?' sorularına yanıt aramaktadır. Bu kitap, modern kültürde, medyanın arkeolojik olarak nasıl tasavvur edileceği meselesine açıkık getirmekte ve bunun nasıl yapılacağına dair bize rehberlik eden çeşitli teorilerin, yöntemlerin ve fikirlerin haritasını çıkarmaktadır. Parikka, kitabında, medya arkeolojisini; eski ve yeni medya, hayali medya, yeni materyalizm, gürültü ve arşiv gibi kavramsallaştırmalar aracılığıla ele almaktadır.

Anahtar kelimeler: Medya arkeolojisi, yeni medya kültürleri, dijital kültür arkeolojileri 


\section{Giriş}

Medya, kültür, tasarım ve tarih alanlarındaki disiplinler arası çalışmalarıyla tanınan akademisyen ve sanatçı Jussi Parikka, medya arkeolojisine dair en güncel ve en kapsamlı çalışma olan Medya Arkeolojisi Nedir? adlı kitabında, görece yeni bir araştırma alanı olarak medya arkeolojisine odaklanmakta ve 'medya aracılığıyla yaşanan çok sayıda pratiğin varoluş koşulları nedir?' sorusuna yanıt bulabilmek için geçmiş medyayla bağlar kurmaktadır. Medya arkeolojisinin temel sorusu, Foucault'nun işaret ettiği şekilde, en yalın haliyle şöyle ifade edilebilmektedir: 'Yaşamımızı sürdürürken kullandığımız şu şeyin, bu ifadenin, şu söylemlerin, medya aracılığıyla yaşadığımız çok sayıda pratiğin varoluş koşulları nedir?' Yine aynı şekilde, medya arkeolojisi, şu temel soruyu da sormaktadır: 'Medya teorisi ne işimize yarar?' (Parikka, 2017, s. 33). Bu kitapta hem kökleri itibariyle medya arkeolojisine benzer akademik ve sanatsal medya disiplinleri bağlamında ön plana çıkan tartışmaların ana hatlarını hem de eski ve yeni medyanın dinamiklerini, bellek kültürlerinin medyatikleşmesini anlamak adına medya arkeolojisini teoriler ve yöntemler şeklinde geliştirebilmek için yeni yönelimler sunulmaktadır. Bu bağlamda, kitap, geçmişlere ve geleceklere, geçmiş-geleceklere ve gelecek-geçmişlere ilişkindir. Ayrıca, Parikka, dijital kültürle, bellekle ve teknik medyayla ilgili gündeme gelen sorulara yanıt bulabilmek için medya arkeolojisinin kendisini sürekli yenilemesi gerektiğini savunmaktadır. Sadece 'olmuş' şeylerin ve geçmiş temaların bir değerlendirmesini sunmamakta, aynı zamanda, geçmiş ve şimdiki medya kültürlerini birlikte ele almak için medya arkeolojisi teorilerinden, yöntemlerinden ve araştırma kültüründen nasıl yararlanabileceğimizi açıklamaktadır.

Bu kitap, medya arkeolojisi ile ilgili mevcut teorilere, araştırmalara ve pratiklere ilişkin yeni yönelimleri ve fikirleri ayrıntılı bir şekilde masaya yatıran yedi bölüme ayrılmaktadır. Bölümlerin sıralaması, kabaca, medya arkeolojisinin evrilme biçimini takip etmektedir. Eski ve Yeninin Kartografileri başlığını taşıyan birinci bölümde, yazar, eski ve yeni medyanın izlerini sürmektedir. Duyuların Medya Arkeolojisi: Görsel-işitsel, Duygulanımsal, Algoritmik başlığını taşıyan ikinci bölümde, medya bağlamlarında, duyularımızın nasıl eklemlendiğine dair bir çözümleme yapabilmek için medya arkeolojisinin iyi bir metodoloji olduğunu öne sürmektedir. Hayali Medya: Tuhaf Nesnelerin Haritasının Çıkarılması başlığını taşıyan üçüncü bölümde, 'hayali medya araştırmaları'na odaklanmaktadır. Medya Teorisi ve Yeni Materyalizm başığını taşıyan dördüncü bölümde, Almanların medya arkeolojisi üzerindeki etkilerini ve 1980 'li yıllardan bu yana çalışmalarıyla hem Alman hem de Anglo-Amerikan medya teorisi ile ilgilenen çevrelerde önemli bir etkiye sahip olan Friedrich Kittler'in 'medya materyalizmi' yaklaşımını ele almaktadır. Gürültünün ve Kazaların Haritasını Çıkarmak başlığını taşıyan beşinci bölümde, gürültüye odaklanmakta ve medya tarihinin alternatif bir okumasını sunmaktadır. Arşiv Dinamikleri: Yazılım Kültürü ve Dijital Miras başlığını taşıyan altıncı bölümde, 'medya arkeolojisi, yazılım kültürlerinde arşivsel olanla ilgili olarak neler söyleyebilir?' sorusuna, Medya Arkeolojisi Uygulamaları: Yeniden Dolayım İçin Yaratıcı Metodolojiler başlığını taşıyan yedinci bölümde ise, 'medya arkeolojisi, sanatsal bir metodoloji olarak nasıl kullanılmaktadır?' sorusuna yanıt aramaktadır. 
Özetle, bu kitap, medya arkeolojisi teorisi ve pratiği ile ilgili tartışmaları hem tanıtmayı hem de ilerletmeyi amaçlamaktadır. Ayrıca, medya arkeolojisi ile ilgilenen okurların ve öğrencilerin fikirlerini ve kavrama yeteneklerini derinleştirmek için onlara konuyla ilgili makaleler ve kitaplar önermektedir. Bu noktada, Huhtamo ve Parikka'nın (2011) Media Archaeology: Approaches, Applications and Implications adlı kitabı özellikle tavsiye edilmektedir. Ayrıca, Parikka'nın (2017, s. 18) medya arkeolojisinin arka planını oluşturduğunu öne sürdüğü çalışmalar da bu öneriler içinde yer almaktadır. Örneğin, Michel Foucault'nun (1926-1984) iktidar ve bilgi arkeolojisi alanındaki çalışmaları, Walter Benjamin'in (1892-1940) modernliğin enkaz yığınlarındaki ilk kazı çalışmaları, 1980'lerdeki 'yeni film tarihi' ve 1990'lardan bu yana dijital kültürleri anlamaya çalışan çeşitli araştırmalar bunlardan bazılarıdır.

\section{Eski ve Yeninin Kartografileri}

Jussi Parikka, kitabının 'Eski ve Yeninin Kartografileri' adlı bu bölümünde, medya arkeolojisinin şimdiyi ve geleceği anlamak için geçmişi kazmakla meşgul olduğunu dile getirmektedir. Ancak, medya arkeolojisinin hiçbir zaman saf bir akademik girişim olmadığını, aksine, 1980'li ve 1990'ı yıllardaki ilk aşamalarından bu yana, 'yeni medya'daki yeniliğin ne anlama geldiğini araştırmak için 'geçmiş medya'dan temaların ve fikirlerin kullanılabildiği bir alan olduğunu ifade etmektedir. Dijital kültür araştırmalarında medya arkeolojisi yönteminin potansiyellerini ayrıntıı bir şekilde inceleyen bu kitap, modern kültürde medyanın arkeolojik olarak nasıl tasavvur edileceği meselesine açıklık getirmekte ve bunun nasıl yapılacağına dair bize rehberlik eden çeşitli teorilerin, yöntemlerin ve fikirlerin haritasını çıkarmaktadır. Medya arkeolojisi, medya kültürlerini, yeni teknolojilerin modası geçmiş hale geleceği zaman dilimlerinin üst üste geldiği bir maddiyat katmanı olarak görmektedir. Bu bağlamda, Parikka, medyanın yasını tutanların geçmişe özlemini şu sözlerle ifade etmektedir (Parikka, 2017, s. 15):

Technics 1200 vinil pikap (1972-2010) ya da Sony Walkman (19782010) üretimine son verilmiştir; manyetik teyplerden çeşitli boyutlarda disketlere kadar kaybolup gitmiş formatları şevkle toplayanlar vardır; 1990'ların başında çıkmış, artık kullanılmayan oyunlar internette bir zombi hayatı sürdürmektedir; medya tüketim pratikleri de retro hale gelmektedir. Sözgelimi, Londra'da son dönemde ortaya çıkmış olan ve plak kaydının neredeyse dini bir ayindeymişçesine kesintisiz çaldığı plak dinleme kulüpleri.

Parikka, yeni medyanın kullanıcı alışkanlıklarını yavaş yavaş değiştirdiğini, ancak, eski medyanın bizi asla terk etmediğini, 'zombi medya' olarak tanımladığı eski medyanın yeniden kullanıldığını, yeniden su yüzüne çıktığını, kendisi için yeni kullanım alanları, bağlamlar ve uyarlanmalar bulduğunu belirtmektedir. Parikka'ya (2017, s. 16) göre, hızlanma ve insani algılama kapasitemizi aşan geçicilikler bağlamında tanımlanan küreselleşmiş enformasyon kültürlerinde, geçmişe olan hayranlığın (vintage) yeniden doğduğu görülmektedir (Resim 1). Aynı şekilde, Hertz ve Parikka (2012) da medya arkeolojisinin; hızla modası geçen teknolojilere ilişkin teorik eleşti- 
rinin, bir kenara atılmış teknoloji modellerinin aktif bir şekilde dönüştürme pratikleri aracılığıyla farklı bir kullanım için yeniden tasarlanmasıyla ilişkilendirildiği bir sanat metodolojisi haline gelebildiğini ve 'zombi medya'nın da medya arkeolojisinin bir sanat metodolojisi haline gelebilme şekline işaret ettiğini öne sürmektedir.

Resim 1: 2010 Pazarlama Kampanyası'ndan Vintage Internet. Maximidia Vintage Ads.

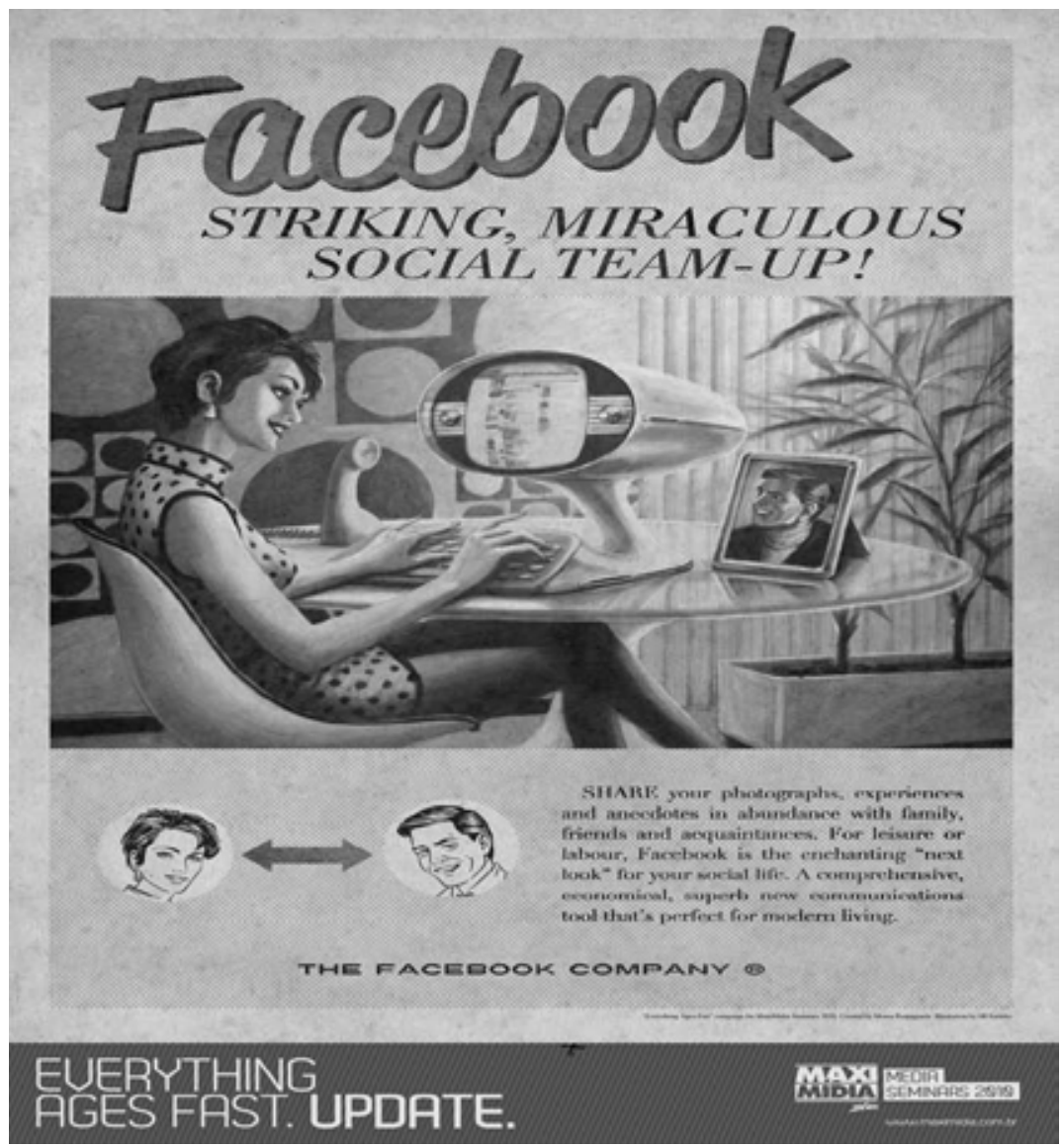

\section{Duyuların Medya Arkeolojisi}

Parikka, kitabının 'Duyuların Medya Arkeolojisi: Görsel-Işitsel, Duygulanımsal, Algoritmik' adlı bu bölümünde, medya bağlamlarında, duyularımızın nasıl eklemlendiğine dair bir çözümleme yapabilmek için medya arkeolojisinin iyi bir metodoloji olduğunu öne sürmektedir. Dokunmatik ekranların ve görsel olmanın ötesine geçen arayüzlerin çağında, yeni dokunsal arayüz biçimleri, duyusal becerileri yeniden örgütlemekte, dokunuşa tepki göstermekte, sesle birlikte hareketi 
de kaydetmekte (PlayStation Move), izlemenin yanı sıra geriye bakmaya da izin vermekte (yüz tanıma) ve duyular ile medya arasındaki ilişkilerin yeni biçimlerde kavramsallaştırıımasını talep etmektedir. Ayrıca, Parikka'ya (2017, s. 58) göre, medya arkeolojisi ile sinema ('yeni film tarihi', erken sinema ve sinema öncesi dönem) arasında yakın bir ilişki vardır. Medya tarihlerini yeni baştan yazmaya yönelik bir girişim olarak medya arkeolojisi film araştırmalarına odaklanırken hem yeni medyayla hem de kültürel bağlamlarla ilgilenmektedir.

\section{Hayali Medya}

Jussi Parikka, kitabında, Gebhard Sengmüller'in enstalasyonunu (Fotoğraf 1), var olmayan, hikâye edilen, kitlesel üretime uygun bulunmayan ya da kaybolmuş ve ölmüş medyaya, yani, hayali medyaya ilişkin fikirlere bir örnek olarak göstermektedir. Bu eser (enstalasyon), medya kültürüne 'ya böyle olsaydı?' sorusuyla yaklaşmaktadır. Aslında, Parikka, bu eser aracılığıyla çok daha önemli bir soruyu gündeme getirmektedir: Neden 'medya kullanımı alışkanlıkları'yla ilgili bazı tasarımlar, teknolojik çözümler ve varsayımlar varlığını korur ve diğerleri kaybolup gider? Parikka, 2010 yllında gerçekleştirilen 'Transmediale' sanat sergisinin bir parçası olan A Parallel Image (Paralel Bir Görüntü) adlı bu enstalasyonun etrafında yürümenin başlı başına bir medya arkeolojik egzersiz olduğunu ifade etmektedir. Sengmüller, hayali medyayı, alternatif tasarım yoluyla hayal etmektedir. Görsel verilerin aktarımı için çok karmaşık bir paralel görüntü aktarımı yönteminin kullanıldığı bu eserde (aygıtta), her piksel, 2500 kablo kullanılarak alıcıya 'doğrudan' paralel olarak gönderilmektedir.

Fotoğraf 1: Gebhard Sengmüller'in A Parallel Image (Paralel Bir Görüntü) adlı enstalasyonu (yerleştirme sanatı)

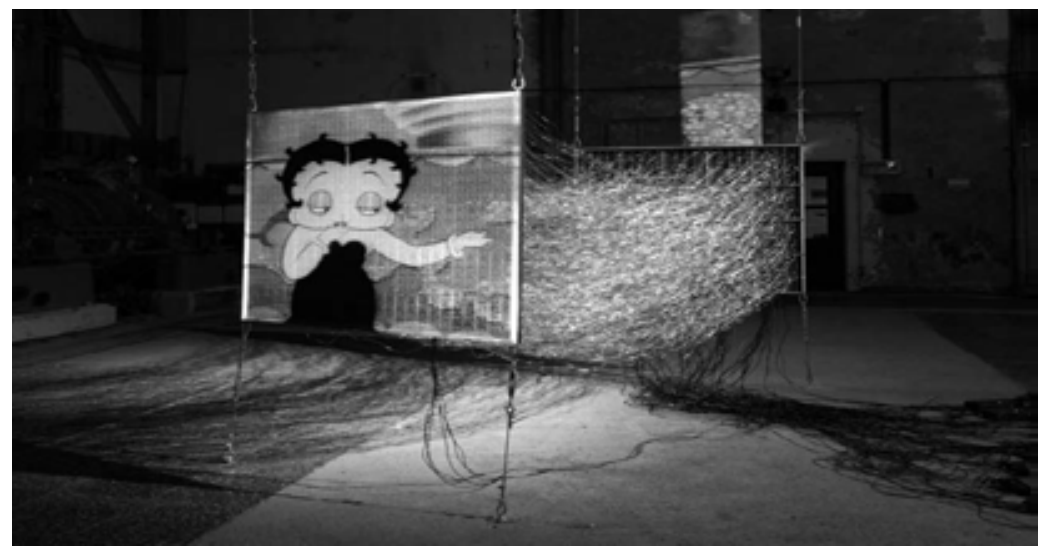

Parikka, kitabının 'Hayali Medya: Tuhaf Nesnelerin Haritasının Çıkarılması' adlı bu bölümünde, 'hayali medya araştırmaları'1na odaklanmaktadır. İmkânsız olanın ve alternatif medya tarihinin yaşayamayan parçalarının 
kavramsallaştııımasından, genellikle resmi medya tarihleri dışında bırakılan alanlar arasındaki iletişime ve medya varyantolojilerine (başkalık bilimi) kadar uzanan geniş kapsamlı hayali medya araştırmalarını incelerken, aynı zamanda, biraz daha somut 'hayali medya' tanımının nasıl yapılabileceğine dair fikir vermektedir. Parikka'ya göre, 'hayali medya' kavramı, medya araştırmalarında ve kitaplarda sıklıkla karşımıza çıkan bir kavram değildir. Çünkü hayallere konu olan ve kimi zaman sadece mucitlerin ve bilim kurgu yazarlarının zihninde var olan medya 'hayali medya'dır. Ayrıca, steampunk² kurguda olduğu gibi, geçmiş zamanlar da yeniden hayal edilebilmektedir. Çok daha önemlisi, bir zamanlar hayali olan, daha sonraları gerçekliğin bir parçası haline gelebilmektedir (Resim 2).

Aslında, hayali medya, geleceğe yönelik bir tahmin (kehanet) medyası değildir. Medya arkeolojisi ve hayali medya, bugün yeni gibi görünenle, ancak, unutulmuş olanla sık sık ilgilenmektedir. Parikka'ya göre, bunun bir örneği, 19. Yüzyıl Fransa'sında kullanılan 'théâtrophone's ${ }^{3} \mathrm{du}$. Théâtrophone, telefonda hem haber hem de eğlence sunmanın bir biçimiydi. Zamanla telefonun bu kullanım biçimi kaybolmuş, televizyon ve radyo yayınlarının gölgesinde kalmıştır. Bu nedenle, bugünkü bakış açısına göre, théâtrophone, tuhaf ve hayali görünmektedir.

Resim 2: 1883 yılında Albert Robida tarafından yazılan Le Vingtième Siècle (Yirminci Yüzyıl) adlı romanda, gündelik hayatı dolduran hayal ürünü medya aygıtlarına dayalı bir gelecek hayal edilmektedir: Telekomünikasyon teknolojileri, hayali araçlar, yeni ekran medyası, izleme ve gözetleme, hava sahası dâhil kent mekânının her köşesini dolduran pazarlama ve markalama.

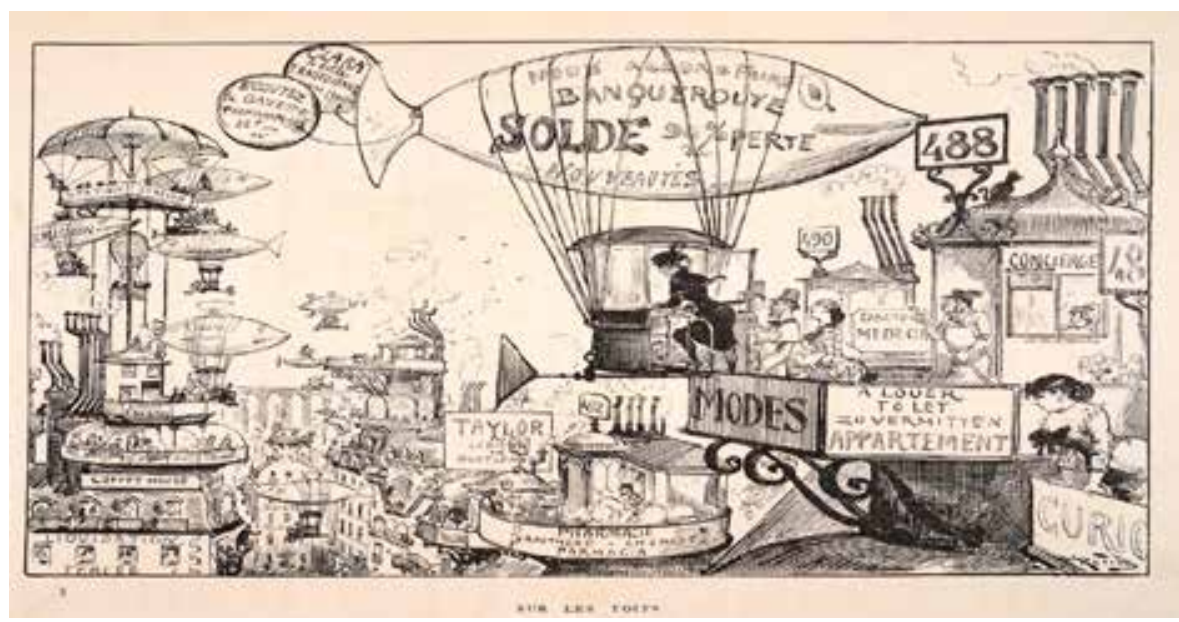

Bütün bunların yanı sıra, Parikka, Zielinski'nin 'hayali medya' ile ilgili ayrımını dikkate alarak, hayali medya kavramının nasıl tanımlanabileceğine dair şöyle bir fikir vermektedir: Kendi zamanlarının dışında olan, yani, icat edilmelerinden ya yüzyıllarca önce ya da yüzyıllarca sonra hayata geçirilmiş olan vakitsiz (zamansız) medya 
ve makineler hayali medyadır. Fiili dünyanın imkânlarının dışında kalan kavramsal medya ve makineler, yani, hiçbir zaman gerçekten doğmamış medya ve aslında yapılamayacaklarını açıkça gösteren, ancak, ima ettikleri anlamların medyanın olgusal dünyasını etkilediği imkânsız medya ve makineler hayali medyanın ta kendisidir.

\section{Medya Teorisi ve Yeni Materyalizm}

Parikka, kitabının 'Medya Teorisi ve Yeni Materyalizm' adlı bu bölümünde, materyalist medya teorisine başvurarak, medya arkeolojisi araştırmalarının; iletişim olaylarının (etkinliklerinin) maddi ontolojilerini ve bunların depolanmasında, dağıtımında ve işlenmesinde yaşanan zorlukları nasıl ayrıntılı bir şekilde ele aldığını gözler önüne sermektedir. Parikka'ya (2017, s. 88) göre, medya arkeolojisi, her zaman geçmiş medya kültürlerinin nesnelerinden, aygıtlarından ve kalıntılarından büyülenmiş ve bunları ana akım medya tarihinin alternatifleri olarak görmüştür (Fotoğraf 2).

Fotoğraf 2: Medya arkeolojisi bir dizi nesneye ve aygıta odaklanmıştır ve bunlar sıklıkla proto-sinematik (ilk sinemaya özgü) nesneler ve aygıtlardır, ama kayıt ve ses reprodüksiyonu (yeniden üretimi) gibi teknik medyanın diğer biçimlerine giderek

artan bir şekilde odaklanmaktadır. Medya arkeolojisi teorileri, sosyal bağlamlara ve örneğin tasarıma ek olarak, kültürün medyatik olarak nasıl depolandığına ve aktarıldığına ilişkin maddi grafikleri ve teknolojileri araştırmak için yapılan incelemelerle de ilgilenmektedir.

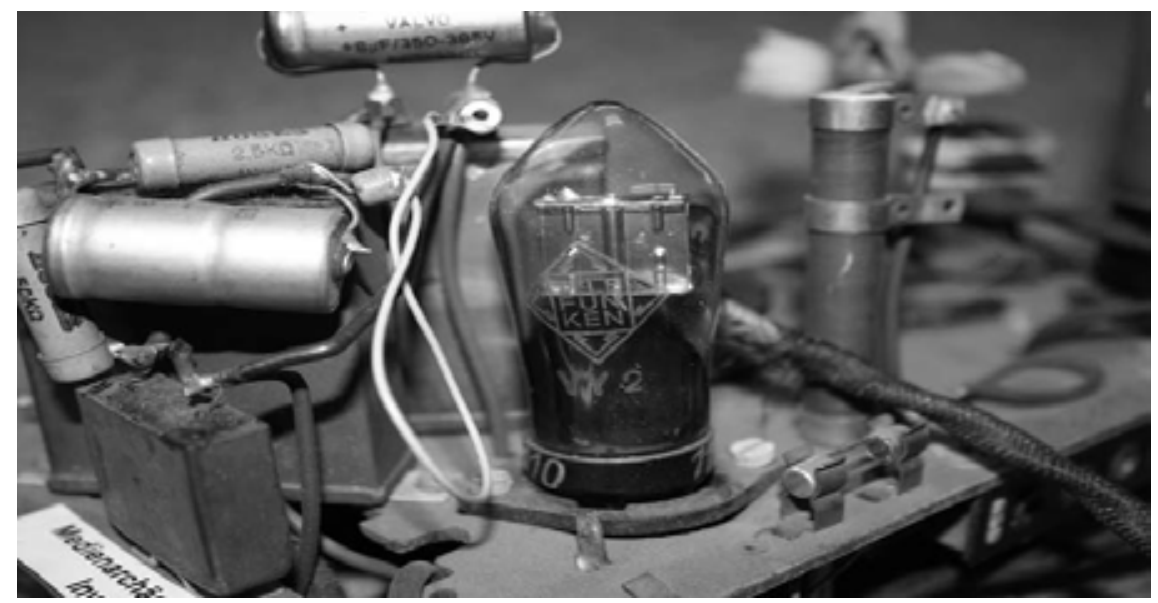

Parikka, bu bölümde, özellikle, Almanların medya arkeolojisi üzerindeki etkilerini ve 1980 'li yıllardan bu yana çalışmalarıyla hem Alman hem de Anglo-Amerikan medya teorisi ile ilgilenen çevrelerde önemli bir etkiye sahip olan Friedrich Kittler'in 'medya materyalizmi' yaklaşımını ele almaktadır. Kittler, medyanın merkezinde, sosyal olanın koşullandırdığı medya içeriğinin, temsilinin ya da imgeleminin değil; sinyalleri fiziksel 
olarak yayan ve etkili bir şekilde kanalize eden 'iletişim eylemi'nin bulunduğunu öne sürmektedir (Parikka, 2017, s. 93). Dolayısıyla, iletişimin metodolojik olarak anlaşılabilmesi için iletişim modelinin (Şekil 1) unsurlarını dikkate almak gerekmektedir.

Medya-materyalist yaklaşımları benimseyen bir başka Alman medya teorisyeni Wolfgang Ernst'tür (Parikka, 2011). Ernst, medya arkeolojisinde, medyanın teknoloji-estetiğine odaklanmakta ve medya arkeolojik bir medya materyalizmi biçimini dile getirmektedir. Anlatıyı, sadece metne ve anlama dayalı bir anlayışa indirgemeyerek, anlatının süreçsel bir işlem olduğunu öne sürmektedir. Bu süreçler, teknolojik sistemlerin bir parçası olan tekniklerdir. Bu nedenle, medya arkeolojisi, kültürel tarih değildir. Medya arkeolojisi, epistemolojisini ve metodolojisini, anlamın dışında kalan her şeyde bulur ve dolayısıyla, söylemsel olmayan unsurlara odaklanmaktadır.

Kittler ve Ernst gibi teorisyenlerin yaklaşımlarını takiben bugün yazılım ve platform araştırmaları gibi 'yeni materyalist' medya araştırmaları ortaya çıkmaktadır. Medya arkeologlarını, donanımların yanı sıra yazılımların da 'kapağını açmaya' zorlayan çözümleme teknikleri uygulanmaktadır. Farklı medya araştırmalarının metodolojilerini benimseyenler, sadece medya kültürlerinin metinsel çözümlemelerine odaklanmak yerine, makinenin içinde olup bitenlere de odaklanmak gerektiğini ısrarla vurgulamaktadır.

\section{Gürültünün ve Kazaların Haritasını Çıkarmak}

Medya arkeolojisi, medya kültürlerinde, anormal olanlarla ve ana akımın dışında kalanlarla ilgilenmektedir (Parikka, 2017, s. 119). Bu bağlamda, Parikka, kitabının 'Gürültünün ve Kazaların Haritasını Çıkarmak' adlı bu bölümünde, gürültüyü ve parazitleri, yani, medya kültürünün anomalilerini ele almakta ve gürültü arkeolojisinin nasıl yapılacağını göstermeye çalışmaktadır.

Şekil 1: Genel bir iletişim sisteminin şeması. Bu şemada, gürültü, her türlü iletişim durumunun asli bir parçası olarak yer almaktadır.

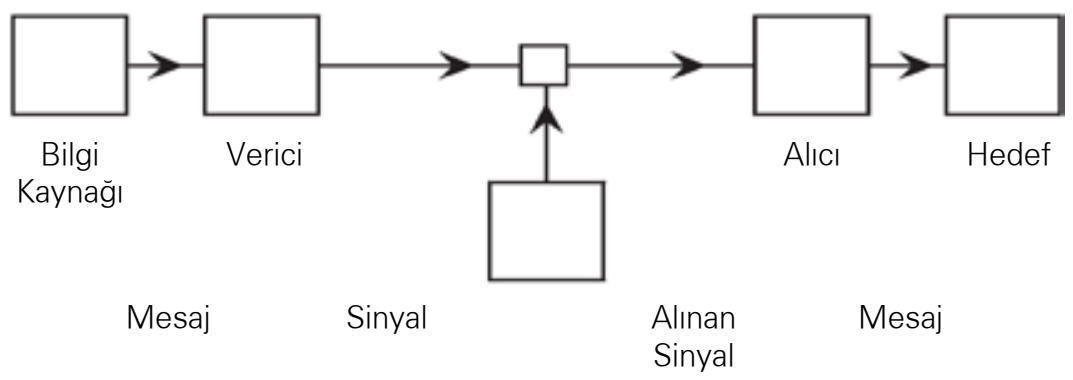


Parikka (2017, s. 120), virüslerin, spam'ların, üç kağıtçıların, hilecilerin ve düzenbazların, teknik iletişim coğrafyamızın bir parçası haline geldiğini; virüslerin ve spam'ların, yani, kültürel pratiklerin, iletişim kanalında, çoğu zaman 'gürültü' fikrine retorik olarak bağı olduğunu öne sürmektedir. Teknik medya kültürünün karanlık yönleri olarak kabul edilebilecek olan bu yönlerine ilişkin çözümlemenin iki önemli öncüsü, Wolfgang Schivelbusch ve Paul Virilio'dur. Her iki isim, medya teknolojileri söz konusu olduğunda, kaza olasıı̆ı̆ının da gündeme geldiğini ifade etmektedir. Aynı şekilde, Parikka (2007) da bir başka çalışmasında, dijital kültürdeki belirli kaza biçimlerine (örneğin, bilgisayar virüslerine) odaklanmaktadır. Ayrıca, Parikka, modern medya kültürünün 'kurucu olayı'nın Claude Shannon (19162001) ve Warren Weaver'ın (1894-1978) yirminci yüzyllın ortasında geliştirdiği iletişim ve gürültü modeli (Şekil 1) olduğunun ısrarla vurgulanmasının Almanlara özgü bir şey olduğunu ileri sürmekle birlikte, gürültünün bir başvuru noktası olduğunu kabul etmektedir. Ona göre de, gürültü iletişimde asli olandır.

\section{Arşiv Dinamikleri}

Medyanın kaderi gözden kaybolmaktır. Medya, aracılık işini yapmakta ve arkasında her şeyin kanallardan akan içerikler olduğu yanılsamasını bırakmaktadır. İşte bu noktada, arşiv büyük bir önem kazanır. Parikka'ya (2017, s. 145) göre, medya arkeolojisi arşivle başlamaktadır. Ancak, medya arkeolojisiyle ilgili çalışmalarda, arşiv fazla tartışımamıştır. Tabii ki, bunun istisnaları da vardır. Örneğin, Wolfgang Ernst, arşiv kavramının ve pratiklerinin görsel-işitsel medya çağında yeniden düşünülmesi gerektiğini dile getirirken, Erkki Huhtamo gibi medya arkeologları da, akademisyenleri göreve çağırmaktadır.

Parikka, kitabının 'Arşiv Dinamikleri: Yazılım Kültürü ve Dijital Miras' adlı bu bölümünde, 'medya arkeolojisi, yazılım kültürlerinde arşivsel olanla ilgili olarak neler söyleyebilir?' sorusuna yanıt aramaktadır. Daha kişisel ve daha kolay ulaşılabilir veri tabanlarıyla ilişkileri bağlamında hem yeni ekonomi ve kapitalizm biçimlerini hem de enformasyon ile kültürün yeni yazı biçimlerini dikkate alarak yeni arşiv kavramlarını ele almaktadır (Parikka, 2017, s. 146-147):

YouTube, Flickr gibi yeni sosyal medya 'arşivleri'nin ortaya çıkmasıyla birlikte, bürokratik arşiv kavramı değişti. Verileri elde etme ve depolama biçimleri değişmiş, merkezi olarak yönetilen, duvarlarla çevrelenmiş mekânların yerini dağınık, yazııma dayalı mekânlar almıştır. Duvarların dışında tutulduğu için çöp olan çöp, sosyal medya kültürlerinde yerini o kadar resmi olmayan yeni arşiv biçimlerine bırakmıştır. Biri için çöp olan şey, bir başkasının yeniden tweet'lediği, retweet ettiği şeydir ya da Facebook'ta paylaştığı linktir; o kadar resmi değildir, ama biçimsellikte hiç de aşağı kalır yanı yoktur, zira formatlar değişip yerlerini daha teknik biçimlere bırakmıştır. 
Parikka, bu bölümde, ayrıca, Wolfgang Ernst'ün medya arkeolojisine ve Berlin'deki Medya Araştırmaları Enstitüsü'nde yer alan Medya Arkeolojisi Arşivi'ne, yaygın ismiyle 'Fundus'a (Fotoğraf 3) odaklanmaktadır. Durağan medya ve teknoloji nesneleri içeren müzelerin ve özel koleksiyonların aksine, bir medya-epistemolojik oyuncak arşivi olarak 'Fundus' hem eski medyaya yönelik bir medya mühendisliği laboratuvarı hem de medya arşivcileri için bir arşivdir. Parikka'ya (2017, s. 170) göre, medya arkeolojik nesneler, süreçsel ve zaman-eleştirel nitelikleriyle canlandırılabilir ve anlaşılabilir. Bu noktada, şu iki soruya yanıt aranmalıdır: 'Medya arkeolojik metodolojilerden en iyi nasıl yararlanabiliriz?' ve 'medya arkeolojisi, dijital beşeri bilimlerdeki bazı tartışmalara nasıl katkıda bulunabilir?'

Fotoğraf 3: Berlin Humboldt Üniversitesi Medya Araştırmaları Enstitüsü'nün bir parçası olan Medya Arkeolojisi Arşivi/Fundus.

Burası eski medya teknolojisinin toplandığı bir havuz ve kurcalama mekânı olmasının yanı sıra, medya arkeolojisinin metinsel bir yöntem olmaktan çıkıp mühendislik çalışmalarıyla ve operasyonel çalışmalarla çözümleme yöntemi haline gelmesi yönünde atılmış bir adımdır.

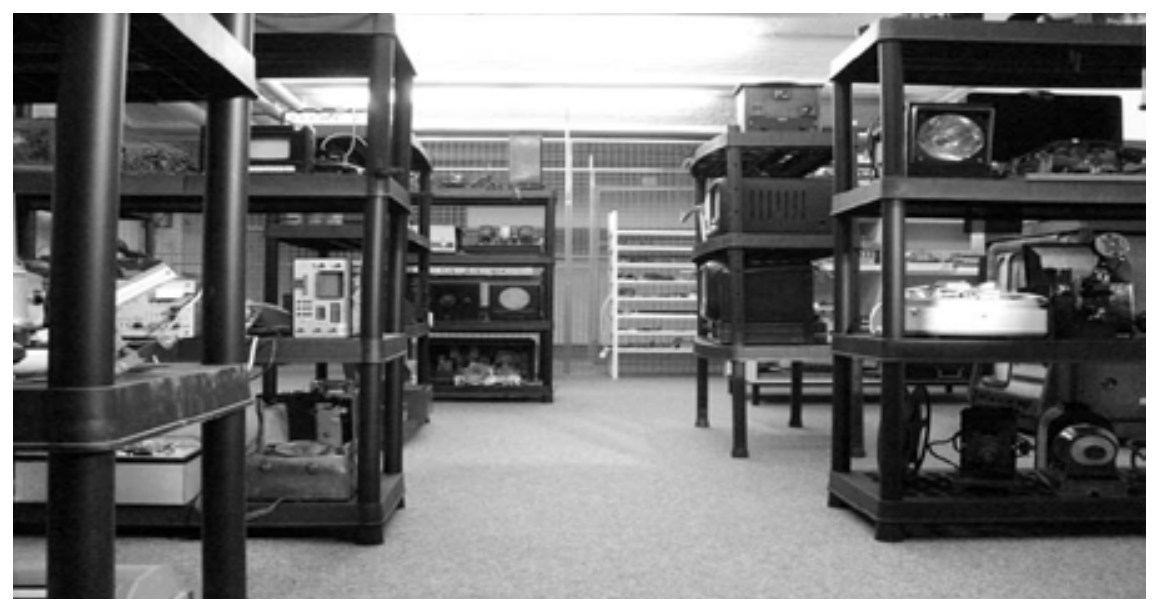

\section{Medya Arkeolojisi Uygulamaları}

Parikka, kitabının 'Medya Arkeolojisi Uygulamaları: Yeniden Dolayım Için Yaratıcı Metodolojiler' adlı bu bölümünde, 'medya arkeolojisi, sanatsal bir metodoloji olarak nasıl kullanılmaktadır?' sorusuna yanıt aramaktadır. Parikka'ya (2017, s. 196) göre, medya arkeolojik sanat yöntemleri hem geçmiş medyaya ilişkin yeni biçimlerden bahseden hem de uygulama yapan bir dizi zengin pratik geliştirmeyi başarmıştır. Paul DeMarinis, Bernie Lubell, David Link ve Zoe Beloff ile birlikte, yakın dönemde ortaya çıkmış yeni sanatçılar da dâhil olmak üzere çeşitli isimler gerçekleştirdikleri çalışmalarda, modası geçmişlik, ilerleme mitleri, 'yeni' medyanın teknik olarak özgün yönleri, geniş kapsamlı alternatif tarihler ve geçmişin hayata döndürülebilecek potansiyelleri 
aracılı̆ııla düşünmenin yeni yollarını araştırmıştır. Ayrıca, Parikka, teknik medyanın ekonomi politiğine, teknolojilerin kara kutularına, bu teknolojilerin ekolojik sonuçlarına ve ihmal edilmiş toplumsal cinsiyet bağlamlarına ilișkin araștırma yöntemleri itibariyle, giderek artan sayıda medya arkeolojik sanat eserinin politik olduğunu öne sürmüştür.

\section{Sonuç}

Jussi Parikka tarafından kaleme alınan Medya Arkeolojisi Nedir? adlı kitap, medya arkeolojisine ilişkin genel bir değerlendirme sunmakta ve medya arkeolojisinin, medya teorisi için ne anlama geldiğini sorgulamaktadır. Ayrıca, 'medya arkeolojik' biçimde nasıl düşünebileceğimizi tartışmaktadır. Bunu yaparken de medya arkeolojisini; eski ve yeni medya, hayali medya, yeni materyalizm, gürültü ve arşiv gibi kavramsallaştırmalar aracılı̆ıyla ele almaktadır. Bu teorik kitap hem eski, klasik (vintage) ve retro hem de yeninin de yenisi, güncelleme ve sürekli yenilenme ile birlikte, arşiv konusunda da teorik tartışmalara yer vermektedir.

Parikka'ya göre, medya arkeolojisi, yaratıcı bir yöntemdir, ancak, yalnızca teorisyenlerin ve tarihçilerin kullandığı bir yöntem değildir. Eski makinelere, fikirlere ve taslaklara bakarak ve aynı zamanda, modası geçmiş teknolojilerle uğraşarak dijital estetiğe dair yerleşik fikirleri sorgulamaya hevesli sanatçılar ve tasarımcılar tarafından da benimsenmektedir. Bu bağlamda, medya arkeolojisi, disiplinlere ait sınırların ötesine geçmektedir.

İdeolojik olarak ve onu disipline edilmiş tarih, sinema, medya çalışmaları ve kültürel çalışmalar disiplinlerinden ayıran liberal özellikleri ve farklılıkları açısından medya arkeolojisi; bu disiplinlerin hakikatle ilgili normlarına ve var olan değerlerine büyük bir tehdit oluşturan disipline edilmemiş bir disiplin olarak anarşik statüsünü korumaktadır (Sobchak, 2011, s. 330).

Huhtamo ve Parikka'ya $(2011$, s. 3) göre, medya arkeolojisi, seyahat halinde bir disiplindir ve hareketli kavramlar dizisine dayanmaktadır. Goddard'ın (2015, s. 1762) ise, medya arkeolojisine ilişkin iki temel varsayımı bulunmaktadır. Birincisi, medya arkeolojisini, yeni bir disiplinden ziyade, Zielinski'yi takip ederek, 'anarchaeology' açısından, modern medya teorileri ve medya tarihi içindeki bir 'kopuş ya da kırılma' olarak tasarlamak ya da değerlendirmek daha iyi olabilir. Íkincisi, medya arkeolojisi; enformasyonel teknolojileri ve süreçleri, halen şekillendirilmemiş ve maddi olmayan koşullar içinde inceleme eğiliminin aksine maddesellik ile medya nesnelerinin, sistemlerinin ve süreçlerinin maddesel ekolojileri üzerinde ısrarla durmaktadır. Ayrıca, medya arkeolojisi, dijital medyaya yönelik Anglo-Amerikan yaklaşımlardan (ampirik olma eğilimindedirler) ve aynı zamanda, niteliksel ve niceliksel araştırmalara dayanan sosyal bilimsel epistemolojilerden farklıdır. Bu bağlamda, medya arkeolojisi, ana akım medya araştırmaları tarafından inmal edilen ya da marjinalleştirilen konulara odaklanan alternatif medya araştırmaları için önemli fırsatlar sunmaktadır. 


\section{Kaynakça}

Goddard, M. (2015). Opening up the Black Boxes: Media Archaeology, 'Anarchaeology' and Media Materiality. New Media\&Society, 17(11), 1761-1776.

Hertz, G. ve Parikka, J. (2012). Zombie Media: Circuit Bending Media Archaeology into an Art Method. Leonardo, 45(5), 424-430.

Huhtamo, E. ve Parikka, J. (Ed.). (2011). Media Archaeology: Approaches, Applications and Implications. Berkeley, California: University of California Press.

Kluitenberg, E. (Ed.). (2006). Book of Imaginary Media: Excavating the Dream of the Ultimate Communication Medium. Amsterdam, Rotterdam: NAi Publishers.

Parikka, J. (2017). Medya Arkeolojisi Nedir? (E. Kılıç, Çev.). İstanbul: Koç Üniversitesi Yayınları.

Parikka, J. (2011). Operative Media Archaeology: Wolfgang Ernst's Materialist Media Diagrammatics. Theory, Culture\&Society, 28(5), 52-74.

Parikka, J. (2007). Digital Contagions: A Media Archaeology of Computer Viruses. New York: Peter Lang.

Sobchak, V. (2011). Afterword: Media Archaeology and Re-Presencing the Past. E. Huhtamo ve J. Parikka (Ed.), Media Archaeology: Approaches, Applications and Implications içinde (323-334). Berkeley, California: University of California Press. 